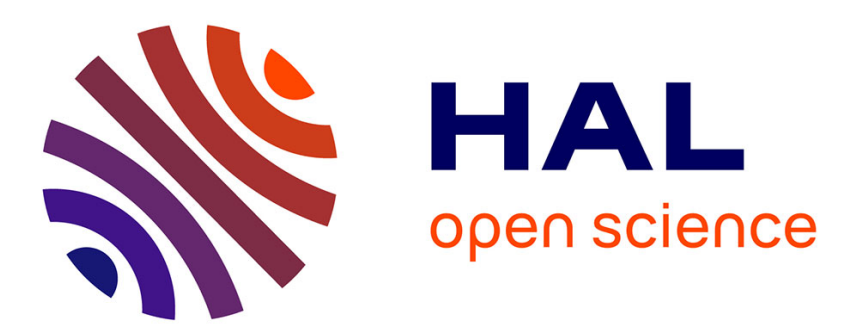

\title{
Teaching durability in automotive applications using a reliability approach
}

\author{
Anne Morel, André Bignonnet, Guénaël Germain, Franck Morel
}

\section{To cite this version:}

Anne Morel, André Bignonnet, Guénaël Germain, Franck Morel. Teaching durability in automotive applications using a reliability approach. International Journal on Interactive Design and Manufacturing, 2010, 4 (4), pp.281-287. 10.1007/s12008-010-0110-8 . hal-00807562

\section{HAL Id: hal-00807562 https://hal.science/hal-00807562}

Submitted on 12 Apr 2013

HAL is a multi-disciplinary open access archive for the deposit and dissemination of scientific research documents, whether they are published or not. The documents may come from teaching and research institutions in France or abroad, or from public or private research centers.
L'archive ouverte pluridisciplinaire HAL, est destinée au dépôt et à la diffusion de documents scientifiques de niveau recherche, publiés ou non, émanant des établissements d'enseignement et de recherche français ou étrangers, des laboratoires publics ou privés. 


\title{
TEACHING DURABILITY IN AUTOMOTIVE APPLICATIONS USING A RELIABILITY APPROACH
}

\author{
Anne Morel $\succ(1)$, André Bignonnet (1-2), Guénael Germain (1), Franck Morel (1) \\ (1) Arts et Métiers ParisTech-Centre d'Angers, 2 bd du Ronceray 49035 Angers Cedex, \\ France \\ (2) Andre Bignonnet Consulting - Fatigue \& Structural Durability, 49750 Beaulieu, \\ France \\ ૪ anne.morel@angers.ensam.fr ; Tel.: +33-2-4120-7343; Fax: +33-2-4120-7320
}

\begin{abstract}
Fatigue phenomena, which appear generally below the yield stress, is the cause of more than $80 \%$ of in-service mechanical failures. However, the optimization of the weight and cost when designing mechanical components or structures, linked to improved performance, leads to increasingly stressed components. Therefore a fatigue design approach must be done by the engineer. This paper shows the experience gained over five academic years of teaching fatigue the assessment of automotive components using a reliability approach to predict probability of failure, in the engineering school, Arts et Métiers ParisTech, in France. The choice was made to present a comprehensive fatigue assessment approach using a method, initially developed in the automotive industry and since extended to the aeronautical and mechanical industries. This method is known as the "Stress-Strength interference analysis". The "Stress" represents the distribution of the driver severity, and the "Strength" represents the distribution of the fatigue strength of all the components. A suspension arm is used to illustrate the approach. The Dang Van multiaxial fatigue criterion is implemented in a Finite Elements Code and a danger coefficient is visualized on the meshed structure. The fatigue analysis is interpreted with respect to the target reliability sought by the car- manufacturer.
\end{abstract}

Keywords Teaching in product design, Probabilistic approach, Fatigue design, Dang Van criterion.

\section{Introduction}

The optimization of weight and cost in the design of mechanical components or structures leads to a better use of materials. However, linked to improved performance, it results in more highly stressed components. Fatigue phenomena, which generally occur below the yield stress can becomes critical. This is the cause of more than $80 \%$ of in-service mechanical failures. Therefore a fatigue design approach must be done by the engineer. This paper gives an overview of the experience gained over five academic years of teaching fatigue assessment of automotive components using a probabilistic approach to guarantee in service reliability and safety.

Arts et Métiers ParisTech is a higher education engineering school whose purpose is to train qualified engineers in the fields of mechanical engineering, power engineering and industrial engineering. Various educational activities are proposed. Among them, the Capability Academic Credits are organized around multidisciplinary and transverse activities. One of the modules is a $40 \mathrm{~h}$-course, which is dedicated to mechanical systems design. In the Education and Research Campus at Angers, the choice was made to present a comprehensive fatigue assessment approach using a probabilistic method, initially developed in the automotive industry and since extended to the aeronautical and mechanical industries. This method is known as the "Stress-Strength interference analysis" [1]. The "Stress" represents the distribution of the driver severity; the "Strength" the distribution of the fatigue strength of all the components. The method uses 
probability distributions of strength and stress to identify the conditions under which a part will fail, as well as the probability of these conditions. A suspension arm is used as a project work to illustrate the approach (figures 1 and 2).

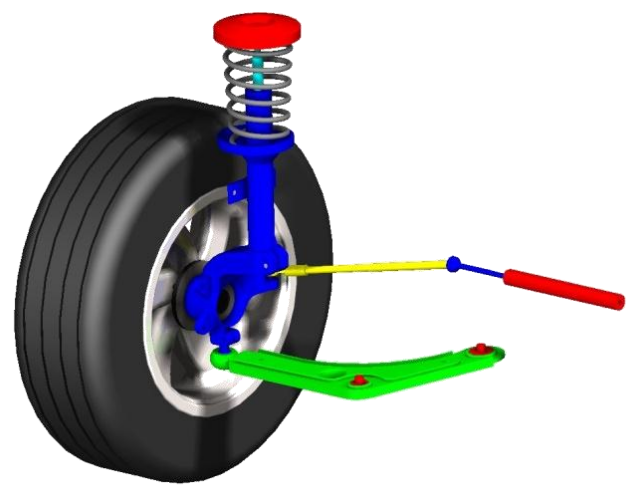

Figure 1. Suspension assembly showing the suspension arm
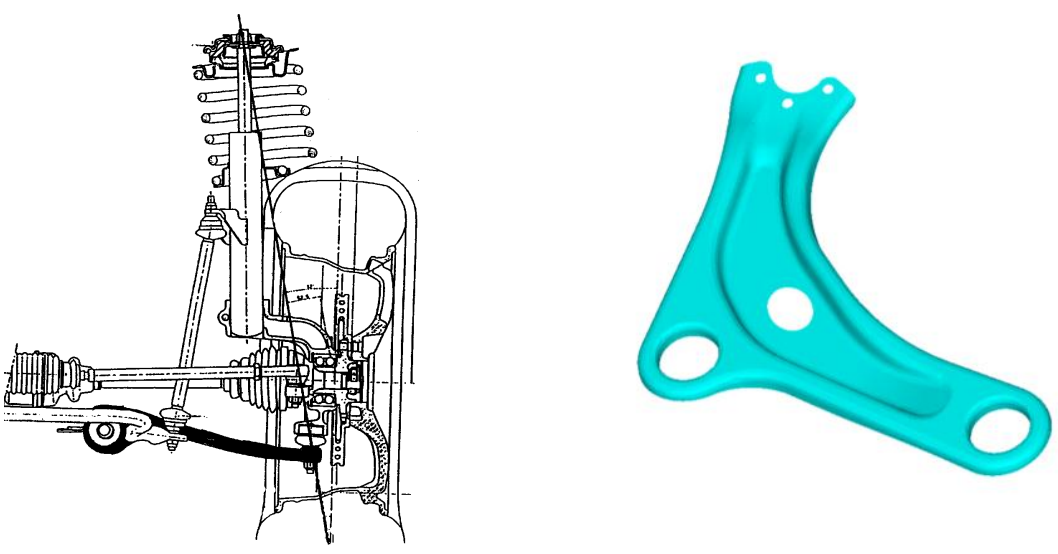

Figure 2. Suspension arm - Context of the part

\section{Design and reliability in fatigue}

Assessing in-service reliability of an automotive component requires taking into account several types of input data (Figure 3). First of all, every customer is different, and all car users drive on different roads. So each vehicle is submitted to different loading conditions. Also, taking into account the intrinsic scatter in material strength and related manufacturing processes, each vehicle has a different resistance. Through experimental investigations, it is possible to determine the material reference fatigue data and its scatter. Even if the scatter is known, it may be very large. However the most difficult issue is to integrate in these data the scatter linked to the fabrication process.

The first reflex to assess reliability is to ensure that the weakest part can withstand the most severe customer or driver. This approach is in fact difficult to implement for two 
reasons: how can the most severe client be defined? It is always possible to find a customer whose driving style is more severe than expected. And how can the weakest component be identified? If these questions could be answered, this simplified reliability approach would lead to the fact that all vehicles would be oversized (except for one in the worst case!).

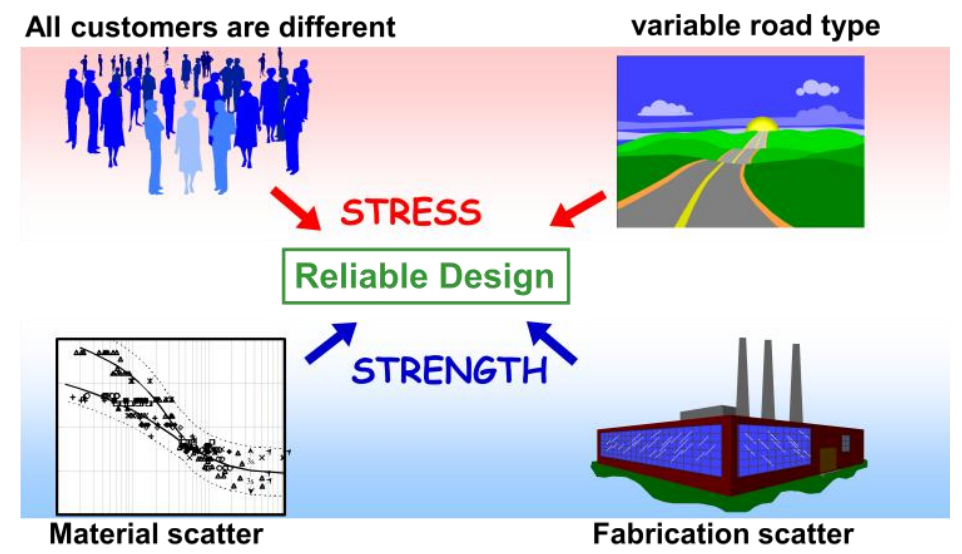

Figure 3. Input data for reliable design

To assess reliability, carmakers prefer to choose a probabilistic vision, as opposed to the maximalist one described above, which relies on the fact that the weakest part probably does not encounter the most severe client. Therefore, the design consists in guaranteeing a reliability $\mathrm{F}$ or accept a risk $\mathrm{R}=1-\mathrm{F}$ of having a problem in service. This approach allows redesigning the minimum of components. In the automotive domain, it is clear that this risk $\mathrm{R}$ must be very small for the failure of suspension components. In practice, a very low value is given to $\mathrm{R}$. Otherwise, it would mean that the failure of some components for a few drivers could be possible, which is unacceptable. Thus $\mathrm{R}$ is chosen to correspond to the societal risk: one chance in one billion of a failure in service.

The overall methodology deals with the relative position of the two distributions: the driver severity and the component strength. The driver distribution is defined by $\left(\mu_{\mathrm{C}}, \sigma_{\mathrm{C}}\right)$ the mean value and standard deviation. So is the strength distribution given by $\left(\mu_{R}, \sigma_{R}\right)$. The use of the "Stress-Strength interference analysis" implies that for a given driver severity distribution, we should know where the strength distribution should be. It can then be assured that the in-service failure risk is lower than the target risk (Figure 4).

A method has to be developed to define the customer severity. This is done by measuring the wheel forces under various driving conditions, in combination with user questionnaires on car usage. This data is analyzed to transform the recorded signal into an equivalent loading (force of constant amplitude versus number of cycle). This equivalent loading is chosen to produce the same fatigue damage than the vehicle will support in its whole life. The methodology is developed in ref [1-2]. Meanwhile the component strength distribution is estimated through production surveys on similar components with the same fabrication process. 


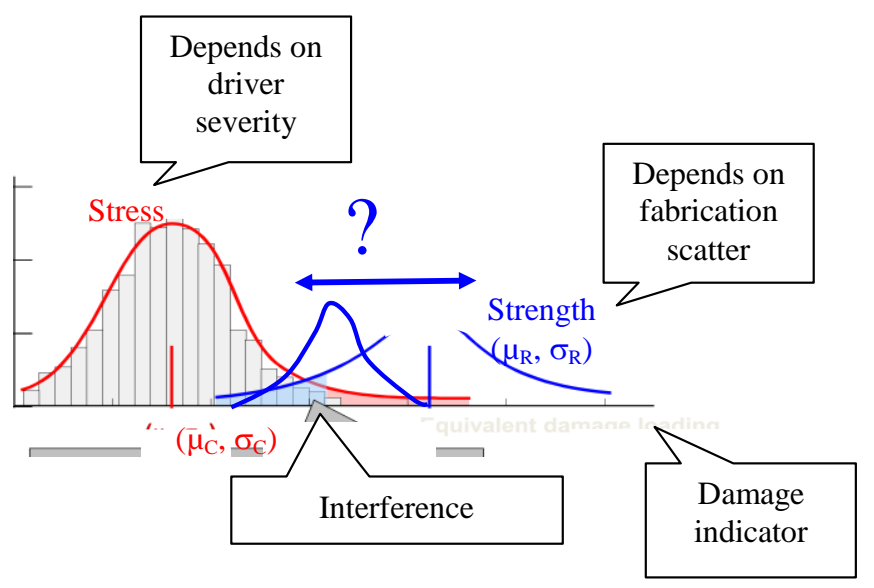

Figure 4. The "Stress-Strength interference analysis" method

To correctly locate the "strength" distribution of the components with regards to the "stress" distribution of the customer severity, automobile engineers rely on two elements. First of all, numerical simulations can be conducted, which requires the definition of an objective customer at a specific position Fn in the customer distribution. A fatigue criterion which can account for the specific loading conditions has to be chosen. The Dang Van multiaxial fatigue criterion is often selected [4-5]. It requires the stress tensors during the fatigue cycle, calculated by Finite Element Analysis. Figure 5 resumes the different steps of this reliability approach. Then an experimental validation must be conducted with the same loading conditions on representative prototypes of the series production and with a acceptance criterion taking into account the production dispersion.
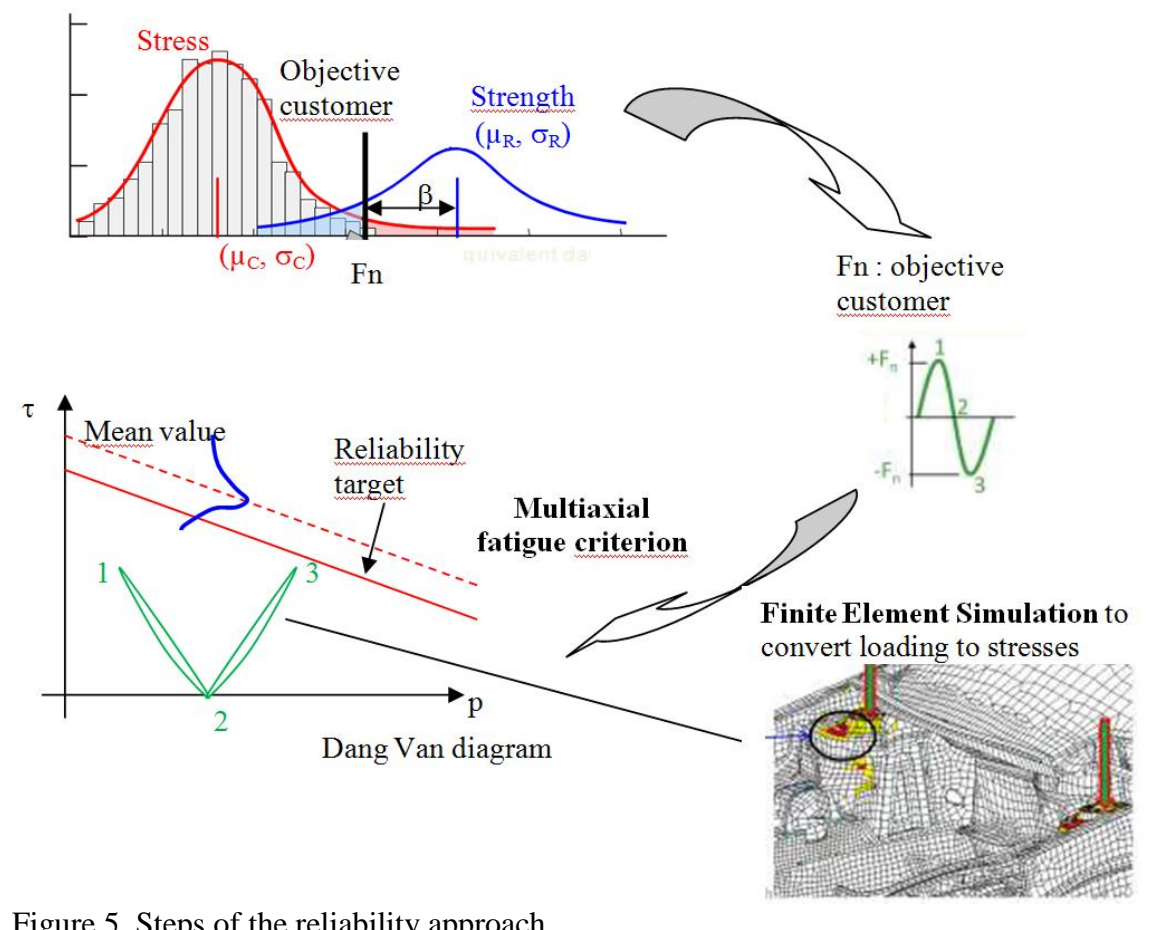

Figure 5. Steps of the reliability approach 


\section{Teaching of the module}

The aim of the module is "learning by doing" or "action learning" [7]. Thus the lectures have to establish the necessary knowledge and skills for carrying out fatigue design of mechanical components in an industrial context. The lectures are briefly presented in the following section.

\subsection{Statistical description and probabilistic analysis}

This lecture strengthens the students' knowledge in statistics and types of statistical distribution, to analyze on one hand:

- in-service measurements useful for the construction of the loading case,

- fatigue test results to quantify the characteristic values of materials behavior as well as their dispersion,

-results of tests on complete structures,

and to drive, on the other hand, a probabilistic analysis to quantify the risk of failure in service.

The strength distribution is assumed to follow a normal distribution (indeed the strength is a combination of many variables). The driver severity may take another form (e.g. lognormal or Weibull). In this case, the failure probability can be computed through various methods, for example a Monte-Carlo Technique can be used to randomly select a sample from each distribution and compare them. After hundreds or thousands of samples have been simulated, the probability of failure can be estimated from the results. If it is assumed that the driver severity follows a normal law, calculating the interference between the two distributions can be done by analytical equations. The random variable $\mathrm{Z}$ can be expressed by Equation 1:

$\mathrm{Z}=\frac{\left|\mu_{R}-\mu_{C}\right|}{\sqrt{\sigma_{R}^{2}+\sigma_{C}^{2}}}$

It also follows a normal distribution

Thus the probability of failure can be expressed as:

$\mathrm{P}_{\mathrm{f}}=\operatorname{Prob}(Z<0)=\operatorname{Prob}\left(u<-\frac{\mu_{Z}}{\sigma_{Z}}\right)=\frac{1}{2 \pi} \int_{-\infty}^{\frac{\mu_{Z}}{\sigma_{Z}}} \exp \left(\frac{x^{2}}{2}\right) d x$

Where $\left(\mu_{\mathrm{Z}}, \sigma_{\mathrm{Z}}\right)$ are mean value and standard deviation of the random variable $\mathrm{Z}$.

\subsection{Experimental methods and materials characterization}

This lecture is linked to practical work. The basic concepts of stresses and strains are revised to give students the necessary analysis tools. A uniaxial servo-hydraulic test machine is available to characterize the fatigue behavior of a material similar to the one that is used in the suspension arm and to construct the Wöhler curves [6].

The exploitation by the students of their own experimental results, and also those of precedent groups highlights the large scatter in fatigue data. 


\subsection{Fatigue behavior modeling}

Basic fatigue analysis concepts are first presented, focusing on the main parameters governing this kind of damage in mechanical engineering. Uniaxial fatigue criteria and representative curves of the material and structures fatigue behavior are presented [6-7]. These basics in fatigue design are a guide for the engineer to design robust components in terms of fatigue damage. Moreover, as the first step of the stress-strength approach is to condense the load history into one equivalent loading, it assumes that the order of the cycles is not relevant in the fatigue analysis. This allows the use of the Miner cumulative damage law [6] which is described during the lecture and states that where there are $k$ different stress magnitudes in a spectrum, each contributing $n_{i}$ cycles, then if $N_{i}$ is the number of cycles to failure of a constant stress, failure occurs when:

$$
\sum_{i=1}^{k} \frac{n_{i}}{N_{i}}=1
$$

This linear damage hypothesis is consistent in the automotive domain, where high cycle fatigue (no plasticity) and random load spectra are concerned.

Secondly, a more detailed analysis of mechanical fatigue behavior highlights the fact that components are submitted to complex loading conditions which require multiaxial fatigue criteria. Therefore a precise and proven methodology for the exploitation of the evolution in time of the complete stress tensor is introduced. Relationships between the micro or the mesoscopic scale, where fatigue damage first appears, and the macroscopic scale (or scale of the engineer) are discussed. The Dang Van endurance criterion [4-6] is used. It is restricted to problems of high cycle fatigue life. More specifically, it links the fatigue limit to the non-propagation of micro-cracks, or from the point of view of the microplasticity, to an elastic shakedown across the grain.

The two mechanical parameters responsible for fatigue damage are the amplitude of the mesoscopic shear stress in the elastic shakedown state $\hat{\tau}(\underline{n}, t)$ and the hydrostatic stress $\Sigma_{H}(t)$. The Dang Van criterion can be written as follows [6, 9]:

$$
\underset{t}{\operatorname{Max}} \operatorname{Max}_{\underline{n}}\left\{\hat{\tau}(\underline{n}, t)+\alpha \Sigma_{H}(t)\right\} \leq \beta
$$

where $\alpha$ and $\beta$ are constants which depend on two fatigue limits obtained from material reference fatigue limits for purely reversed torsion and tension.

This criterion has been proved particularly efficient in the industrial context for the treatment of multiaxial loadings. It is also widely implemented in the transport industries (rail, aerospace and automotive). One of its main advantages is to handle the phenomena at a microscopic scale through mechanical parameters at the macroscopic scale.

Thus the fatigue assessment of the suspension arm is examined according to this criterion by the students.

\subsection{Industrial practice of design for reliability}

This section exposes the practice of reliability design using the "Stress-Strength interference analysis" method as it is used by automotive designers [3]. The determination of the Strength distribution includes the scatter due to the fabrication process. It is determined from fatigue tests on structural elements that are representative of the material and manufacturing process of the component. The capitalization lies in the use of the coefficient of variation $\mathrm{q}$ which is the standard deviation divided by the mean value of the fatigue strength. This allows enhancing the confidence level of the statistical parameters as a function of the number of test in the strength data base. 
The application of the "Stress-Strength" Method also requires the knowledge of the customers' severity. This information is accessible as statistical distributions obtained via customer surveys on car usage. On the one hand a "car usage" survey allows conditions in which cars are driven (loading and type of road) to be known. On the other hand an "owner behavior" enquiry allows the determination of the distribution of the owners' severity. The handling of these statistical distributions leads to the establishment of the acceptance criteria, from calculations and/or tests using probabilistic analysis to ensure the reliability of the vehicle for all customers. Practical exercises from measurements carried out on load sensor equipped cars are conducted. The customers' severity is qualified using an equivalent damage loading scalar value Fn. The Design load or technical specification is then defined as severe usage with a low probability of occurrence (1/50 000 in the case of automotive chassis parts).

In addition, an explanation of the choice of the combination of the material and the manufacturing process for the suspension arm is done on the basis of technical and economic arguments.

\subsection{Finite element method and fatigue analysis}

To prove the efficiency of this methodology in an industrial context, a student project is proposed during which all the elements of the module are used to design a suspension arm with the Stress-Strength approach. The emphasis is on the notion of the loading cycle. The car manufacturer's specifications are reformulated and analyzed with statistical tools to obtain an equivalent loading cycle. A model of the suspension arm is developed with 4-node shell elements in a Finite Element Code. The material behavior is supposed to be elastic linear which is consistent in high cycle fatigue where there is no cyclic plasticity at the macroscopic scale. The boundary conditions corresponding to the equivalent loading cycle are introduced. Figure 6 gives for example the results obtained in a statical type analysis in terms of von Mises equivalent stresses.

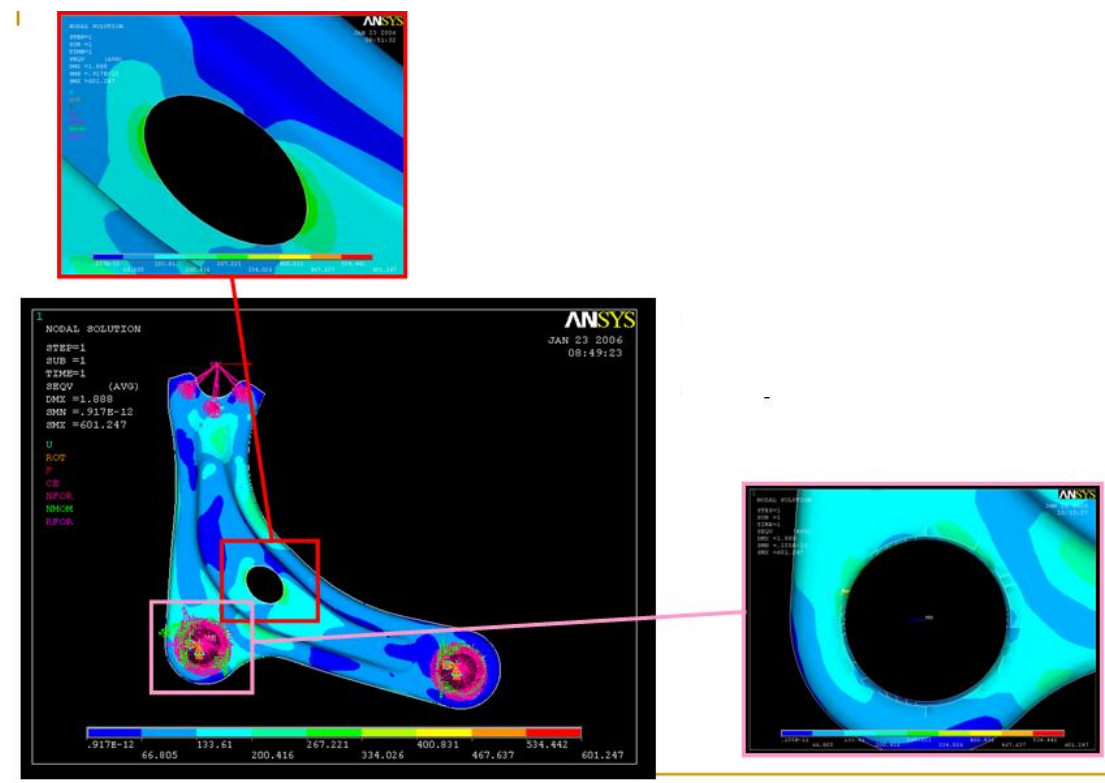

Figure 6. Von Mises Equivalent Stress observed in the suspension arm. 
Fatigue life prediction is the post processing stage of the Finite Element Analysis as proposed by other authors [11]. Using Ansys Parametric Design Language (APDL) [10], the Dang Van criterion is implemented in the Finite Element Code.

In order to simplify the viewing of fatigue criterion predictions, a safety coefficient defined by $d=\underset{t}{\operatorname{Max}} \operatorname{Max}_{\underline{n}}\left\{\frac{\hat{\tau}(\underline{n}, t)}{\beta-\alpha \Sigma_{H}(t)}\right\}$ is introduced and calculated at each node of the FE mesh. The fatigue criterion is set as the mean value of the fatigue strength minus a given number of standard deviations, defined from a probabilistic analysis to guaranty the desired level of reliability taking into account the severity of the design load and the confidence level in the analysis. When $d$ is greater than 1 , the probability of initiating a crack (and therefore fatigue failure) is above the objective value; the design must be reiterated or optimized. When $\mathrm{d}$ is less than 1 , no crack is expected to initiate with the objective level of reliability.

The Dang Van criterion is calculated and depicted in each node in the mesh structure. The fatigue analysis is interpreted with respect to the target reliability sought by the carmaker.

Figure 7 represents the distribution of the Dang Van danger coefficient and is used to locate potential fatigue crack initiation zones. In the present case, the probabilistic approach leads to a danger coefficient less than 1 . This component is correctly designed with regards to the objective reliability.

To understand the specifics of this fatigue design, it is interesting to compare figures 6 and 7 and to see that critical areas are different in both approaches. A "classical" plasticity approach will therefore not correctly predict the real critical areas in fatigue.

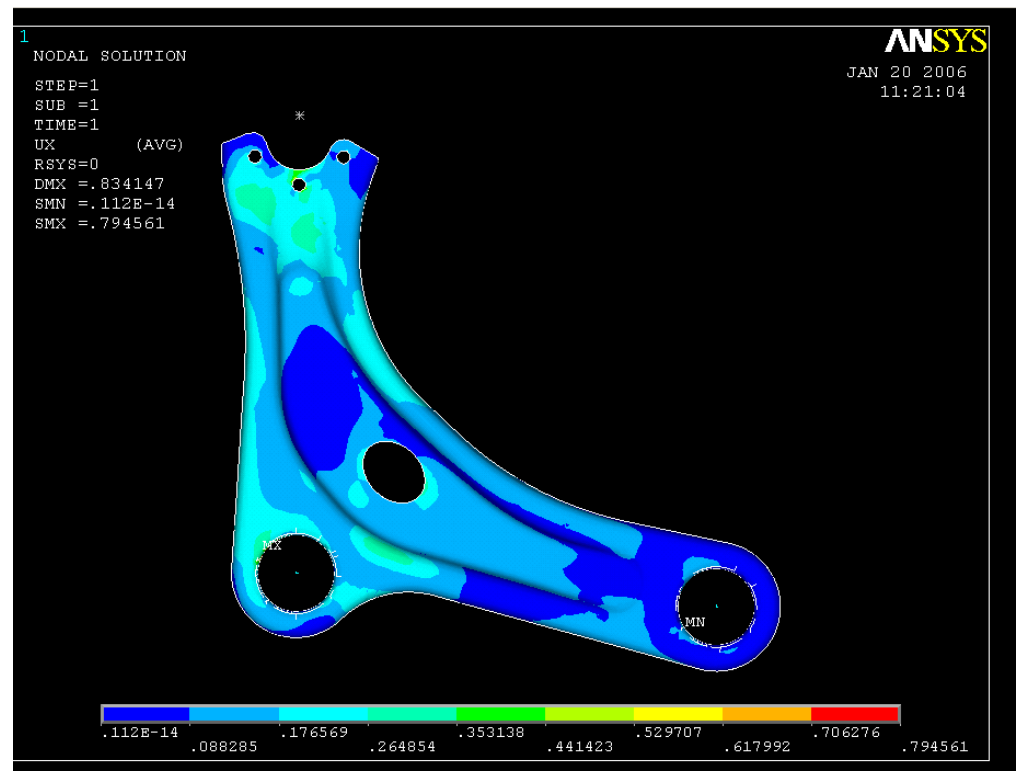

Figure 7. Dang Van danger coefficient implemented in post-processing stage of the Finite Element Code and observed in the suspension arm.

\subsection{Evaluation of the module}


An evaluation of the module was carried out by the engineering school Arts et Métiers ParisTech, including a questionnaire sent to all the students. The percentage of students who responded was $78 \%$. The purpose was to determine the students' attitude to the contents of the program, and the expectations to their preparation for the profession.

The students' feedback was globally positive. The industrial frame was particularly appreciated. By analyzing the problems in depth the students learn and use the disciplines and theories which are considered to be necessary to solve the problems posed.

This module allows each student to acquire the necessary basic knowledge by means of lectures and bibliography. The project work allows the ability to formulate, analyze and solve relevant problems. This "learning by doing" module gives the graduates the experience to enable them to solve the problems they will face in their future professional life.

The interesting feature of the method is a broad insight into and understanding of the connections between different fields and skills, in order to be able to function in an everchanging society.

\section{Conclusions}

A comprehensive approach of fatigue design by a probabilistic approach known as the "Stress-Strength interference analysis" is proposed during a module with 40h-course work in mechanical engineering at the engineering school Arts et Métiers ParisTech, in France.

The changes between conceptual teaching and education practice are surprising. It promotes reflection and leads to the construction of progressive links between the different parts of the module. The implementation of the Dang Van criterion in a finite element code finalizes the teaching and use of all the tools discussed in the module. Thus the students deal with real problems which can be solved by theories and knowledge they have acquired in their lectures.

The project work seems to be helpful for the students to realize that inter-disciplinary problems existing in industry, and prepares them to handle similar problems they will have to deal with in their future professional lives.

\section{References}

[1] Thomas, J.J., Bignonnet, A., Perroud, G.: Fatigue Design and Experimentations with Variable Amplitude Loadings in the Automotive Industry. Fatigue Testing and Analysis Under Variable Amplitude Loading Conditions, ASTM STP 1439, P.C. McKeighan and N. Ranganathan, Eds American Society for Testing Materials, West Conshohocken, PA, 2005.

[2] Johannesson, P., Thomas, J.J.: Extrapolation of rainflow matrices, preprint of Chalmers University, Goteborg (2000)

[3] Bignonnet, A.: A global approach to lightening vehicles. Mécanique et Industries, Vol. 2, Issue 3, 173-180 (2001)

[4] Dang Van, K.: Sur la résistance à la fatigue des métaux. Sciences et Techniques de l'Armement, $3^{\text {ème }}$ fascicule, 47, 647-722 (1973) 
[5] Dang Van, K., Papadopoulos, I. V., Giveau, B., Message, O. : Sur le calcul des structures soumises à la fatigue multiaxiale. Hermès, Paris, pp. $79-97$ (1987)

[6] Henaff, G., Morel, F.: Fatigue des Structures. Collection TechnoSup, Ellipses, (2005)

[7] Stephens, R. I., Fuchs, H. O.: Metal Fatigue in Engineering. Second edition ed., John Wiley \& Sons, Inc. (2001)

[8] Kjersdam, F., Enemark, S.: The Aalborg Experiment: Project Innovation in University Education. Aalborg, Danemark : Aalborg University Press (1994)

[9] Dang Van, K., Bignonnet, A.: A unified model of fatigues 15 years of success in automotive and railway applications. Materialpruefung/Materials Testing 50 (5), 286-293 (2008)

[10] ANSYS - Release 11.0 Documentation for ANSYS

[11] Bishop, N., Sheratt, F.: Finite Element Based Fatigue Calculations. The international Association for the Engineering Analysis Community Netherlands : NAFEMS Ltd (2000) 